\title{
Preparation, molecular structure, vibrational and photoluminescence study of a novel compound based chlorocadmate (II) material
}

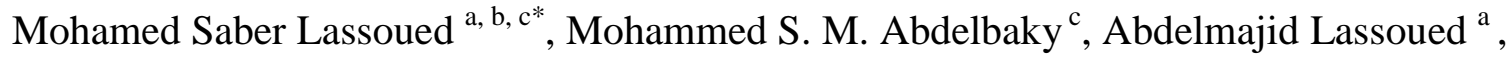 \\ Salah Ammar ${ }^{\text {a }}$, Abdellatif Gadri ${ }^{a}$, Abdelhamid Ben Salah ${ }^{\mathrm{b}}$ and Santiago García-Granda ${ }^{\mathrm{c}}$ \\ ${ }^{a}$ Unité de recherché Electrochimie, Matériaux et environnement UREME (UR17ES45), \\ Faculté des Sciences de Gabès, Université de Gabès, Cité Erriadh, 6072 Gabès, Tunisie \\ ${ }^{b}$ Material and Environment Science Laboratory, Science Faculty of Sfax University, P.B \\ 1171, 3000 Sfax, Tunisia \\ ${ }^{c}$ Department of physical and analytical chemistry, Oviedo University-CINN,33006 Oviedo, \\ Spain
}

*Corresponding author: E-mail address: mohamedlassoued737@gmail.com

\begin{abstract}
:
In the present work, we synthesized a new hybrid compound, $\left(\mathrm{C}_{6} \mathrm{H}_{10} \mathrm{~N}_{2}\right)_{2} \mathrm{Cd}_{3} \mathrm{Cl}_{10}$. The crystal structure, vibrational and photoluminescence properties of the compound were studied. The structure can be described by the alternation of two different cationic-anionic layers. It consists of $\mathrm{Cd}_{3} \mathrm{Cl}_{10}$ dimers anions and bis Orthophenylenediammonium $\left(\mathrm{C}_{6} \mathrm{H}_{10} \mathrm{~N}_{2}\right)$ cations, which are connected via $\mathrm{N}-\mathrm{H} \cdots \mathrm{Cl}$ hydrogen bonds forming a chain network. Furthermore, the 3D Hirshfild surfaces and the associated 2D fingerprint plots were investigated for intermolecular interactions in the molecule. The $\mathrm{X}$ ray powder is in agreement with the $\mathrm{x}$ ray structure. The Infrared Spectrum recorded in the $4000-400 \mathrm{~cm}^{-1}$ frequency region was compared with those found for homologous compounds in the literature. Solid state ${ }^{13} \mathrm{C}$ NMR spectrum shows three signals, confirming the solid state structure determined by X-ray diffraction. Finally the characteristic exciton peaks in absorption spectra are located at 250 and $494 \mathrm{~nm}$ and the photoluminescence measurements showed one peak at around $2.06 \mathrm{eV}$.
\end{abstract}

Keywords: Organic- inorganic hybrid; $\mathrm{X}$ - ray diffraction; SEM; Optical and photoluminescence study. 


\section{Introduction}

Recently, more interest in the field of equipment science has been prompted by the development of new compounds which not only meet the demands of new and innovative technology but are also compatible with the environment. For this reason the research of novel functional materials has allotted much attention to organic-inorganic hybrid materials regarding their attractive physical and chemical properties which include luminescence, optical activity and thermal stability [1-4]. The organic-inorganic hybrid materials are a nanomaterials belonging to the monoammonium and diammonium series [5-7]. An important class of low dimensional hybrid materials is the organic inorganic perovskite-like family of the type $\mathrm{RxMyXz}$ (where $\mathrm{R}$ is protonated amine, $\mathrm{M}$ is a metal and $\mathrm{X}$ is a halide), which has received considerable interest over the last few decades.

Moreover, the materials based on substituted complex ammoniums with halogenated metals such as $\mathrm{Hg}, \mathrm{Cd}, \mathrm{Zn}, \mathrm{Cu}$ etc. present very interesting physical properties [8-12]. In this case the $\mathrm{Cd}$ (II) ion, being a d ${ }^{10}$, was chosen because of its adoption of a variety of coordination numbers and geometries [13-16] depending on the crystal packing and ligands where the anionic sub-lattice of the crystal may consist of either a simple discrete octahedral, onedimensional chain, or a two- to three-dimensional anionic framework $[17,18]$. Therefore, the coordination chemistry of Cd (II) ions with such ligands is of interest.

In an attempt to study the properties of hybrid materials in this paper, a new compound, i.e., $\left(\mathrm{C}_{6} \mathrm{H}_{10} \mathrm{~N}_{2}\right)_{2} \mathrm{Cd}_{3} \mathrm{Cl}_{10}$, was synthesized using slow evaporation methods. The obtained phase was characterized using X-ray diffraction; it displayed a complete crystal structure (at room temperature). This structural study was followed by the intermolecular interaction in the crystal structure, which was investigated by Hirshfeld surface method, X ray powder, Scanning electronic microscopy (SEM), Fourier transform infrared spectroscopy (FTIR), 
Solid-state Cross-Polarization Magic Angle Spinning Carbon-13 Nuclear Magnetic Resonance CP/MAS-NMR measurements as well as optical and photoluminescence study.

\section{Experimental}

\section{1. Material methods}

The title compound crystal was prepared according to the following chemical equation:

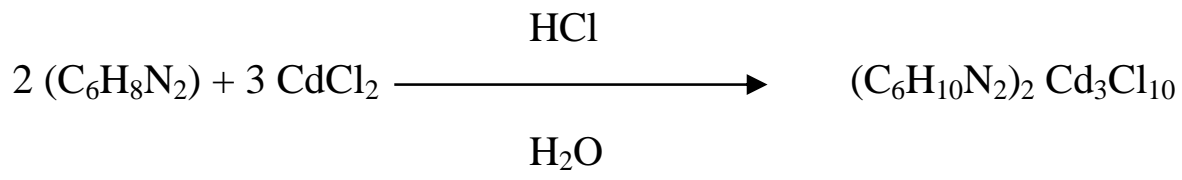

The organic-inorganic compound was prepared by the reaction of 1,2 ortho Phenylenediamine, $\left(\mathrm{C}_{6} \mathrm{H}_{8} \mathrm{~N}_{2}\right)$, and Cadmium (II) chloride $\left(\mathrm{CdCl}_{2}\right)$. First, anhydrous 1,2 ortho Phenylenediamine powder dissolved in an aqueous solution of $\mathrm{HCl}(37 \%)$ was added to the solution of Cadmium (II) chloride in water at a molar ratio of 2:3. The resulting solution was well stirred then kept at room temperature. After 10 days, colorless and prismatic monocrystals of very high quality crystals of $\left(\mathrm{C}_{6} \mathrm{H}_{10} \mathrm{~N}_{2}\right)_{2} \mathrm{Cd}_{3} \mathrm{Cl}_{10}$ appeared in the solution. A single crystal suitable for X-ray diffraction analysis was selected and studied.

\section{3. Investigation techniques}

The characterization of the prepared compound was performed using X-ray diffraction, Hirshfeld surface, Scanning electron microscope (SEM), Nuclear magnetic resonance (NMR), Infrared, optical and photoluminescence analyses.

\subsubsection{Structure determination}

A single crystal was selected for structural analysis by X-ray diffraction. The intensity data were collected on a Bruker AXS CCD area detector system equipped with graphite monochromatic MoKa radiation (0.71073 $\AA$ ) at 296 (2) K. Lattice parameters were refined from setting angles of 434 reflections in $2.1<\theta<25.6^{\circ}$. The empirical absorption corrections 
were based on multi-scan. A total of 8203 reflections were collected using the $\omega-2 \theta$ scan technique, 1896 of which had $I>2 \sigma$ (I) and were used for the structure determination. The crystal structure was solved in the triclinic symmetry, space group $P-1$, according to the automated search for space group available in WINGX [19]. Cadmium and chlorine atoms were located using the Patterson method with the SHELXS 86 program [20].The organic moieties were found from successive difference Fourier calculations using SHELXL 97 [21]. The refinement was done by full-matrix least squares methods (SHELXL 97 program) and converged to an acceptable final agreement factor. The crystal data and structural refinement details of the title compound are presented in Table 1. All the hydrogen atoms were placed geometrically and refined isotropically. The last cycle of refinement included the atomic coordinates for all the atoms, anisotropic and isotropic thermal parameters whose values are listed in Table S1 and Table S2. The structural graphics of the asymmetric unit were created using DIAMOND [22] and Ortep program [23].

\section{3.2. Hirshfeld surface}

To further undress the atomic interactions in the crystal structure, we have determined the Molecular Hirshfeld surfaces which are defined as the volume of space where molecule electron density exceeds that from all neighboring molecules [24, 25] and quantified by means of the Crystal Explorer package using the CIF file format [26].

For each point on the iso-surface two different types of distances are defined: one is de which is the distance to the nearest atoms outside and $d_{i}$, which is the distance to the nearest nucleus inside the surface, are readily defined. The normalized contact distance $\left(\mathrm{d}_{\text {norm }}\right)$ based on both $d_{e}$ and $d_{i}$ was given by the following equation:

$$
\mathbf{d}_{\text {norm }}=\frac{d i-r i^{v d w}}{r i^{v d w}}+\frac{d e-r e^{v d w}}{r e^{v d w}}
$$

Where $r i^{v d w}$ and $r e^{v d w}$ are the van der Waals radii of the atoms. 


\section{3.3. X-ray powder}

The X-ray powder diffraction (PXRD) was recorded on a Siemens D5000 powder diffractometer using $\mathrm{Cu}-\mathrm{Ka}$ radiation $(1.542 \AA)$ with a $2 \theta$ range of $10-70^{\circ}$. The simulation of the PXRD spectra was carried out by the single-crystal data and Oscail (4.6.1) program.

\section{3.4. Micrographs and X-ray microanalysis}

Micrographs and X-ray microanalysis (SEM/EDX) were recorded with a JEOL- 6610LV electron microscope operating at $30 \mathrm{kV}$ coupled with an Oxford X-Max microanalysis system (EDX).

\section{3.5. Solid-state Cross-Polarization Magic Angle Spinning Carbon-13 Nuclear Magnetic}

\section{Resonance (CP/MAS-RMN) Spectroscopy}

The ${ }^{13}$ C MAS NMR spectra were recorded at room temperature by means of a Brucker DSX300 spectrometer. The spectra were acquired with the use of cross-polarization for protons with $12 \mathrm{~ms}$ contact time. A powdered sample was packed in a $4 \mathrm{~mm}$ diameter rotor and set to rotate at a speed of up to $8 \mathrm{kHz}$ in a Doty MAS probe head. The chemical shifts were referenced with respect to dimethyl sulfoxide (DMSO).

\section{3.6. Spectroscopic measurements}

The Fourier transform infrared spectroscopy (FT-IR) spectra were obtained using a Nicole Impact 410 FT-IR spectrophotometer with a sample depressed in $\mathrm{KBr}$ pellet in the $400-4000 \mathrm{~cm}^{-1}$. Moreover, optical absorption spectra of the compound were measured at room temperature using a conventional UV-vis absorption spectrometer (Shimadzu UV 3101). Solid photoluminescence spectra were taken using a time-resolved Edimbugh Instruments FLSP920 spectrofluorimeter with a Red-PMT detector and a Xe bulb as an excitation source. 


\section{Results and discussion}

\subsection{Description of the structure}

The structure of a new compound was developed in the centro-symmetric space group P-1with two formula units in unit cell $(\mathrm{Z}=1)$; the unit cell dimensions were $a=6.8331(8)$ $(\AA), b=9.8525(12)(\AA), c=10.3750$ (14) $(\AA)$ and $\alpha=103.463(5)^{\circ}, \beta=96.344(5)^{\circ}$ and $\gamma=109.450(5)^{\circ}$.

As it can be noticed in Fig. 1, the asymmetric unit of the title compound comprises The asymmetric unit of $\left(\mathrm{C}_{6} \mathrm{H}_{10} \mathrm{~N}_{2}\right)_{2} \mathrm{Cd}_{3} \mathrm{Cl}_{10}$ consists of two atoms of cadmium $\mathrm{Cd} 1$, which is located in an inversion center, $\mathrm{Cd} 2$, and one $\left(\mathrm{C}_{6} \mathrm{H}_{10} \mathrm{~N}_{2}\right)^{2+}$ cation, Thus, owing to the symmetry requirements in P-1. The asymmetric unit should formally be written as a $\left[\mathrm{Cd}_{1 . .5} \mathrm{Cl}_{5}\right]^{2-}$ anion with own diprotonated cation $\left(\mathrm{C}_{6} \mathrm{H}_{10} \mathrm{~N}_{2}\right)^{2+}$. The projection of the atomic arrangement of $\left(\mathrm{C}_{6} \mathrm{H}_{10} \mathrm{~N}_{2}\right)_{2} \mathrm{Cd}_{3} \mathrm{Cl}_{10}$ prolonged following the $a$-axis (Fig. 2). The organic group was located in the plane $(b c)$ at approximately $\mathrm{x}=0$ and $\mathrm{x}=2 / 4$. Besides, the inorganic part was arranged in parallel layers separated by the $\left(\mathrm{C}_{6} \mathrm{H}_{10} \mathrm{~N}_{2}\right)^{2+}$ cations.

In the present structure, there are two types of six-coordinated $\mathrm{Cd}$ were observed: $\mathrm{Cd}$ (1) $\mathrm{Cl} 6$ and $\mathrm{Cd}$ (2) Cl6. In the trimmer, two $\mathrm{Cd}(2) \mathrm{Cl} 6$ octahedra were generated by a symmetric center sharing one bridging chlorine atom $\left(\mathrm{C} 1(3), \mathrm{C} 1\left(3^{1}\right)\right)$, the $\mathrm{Cd}(1) \mathrm{Cl} 6$ octahedron shares one bridging chlorine atom $(\mathrm{C} 1(6), \mathrm{C} 1(3))$ with the $\mathrm{Cd}(2) \mathrm{Cl} 6$ octahedron and another bridging chlorine atom $\left(\mathrm{C} 1(3), \mathrm{C} 1\left(4^{1}\right)\right)$ with $\mathrm{Cd}(2)$ ' $\mathrm{Cl} 6$ (Fig. 3). The $\left[\mathrm{CdCl}_{6}\right]$ octahedron had a slightly distorted octahedral geometry. The bond angles of $\mathrm{Cl}-\mathrm{Cd}-\mathrm{Cl}$ were in the range of $80.92-168^{\circ}$ and deviated slightly from the ideal octahedral values $\left(90^{\circ}\right.$ and $\left.180^{\circ}\right)$ (Table 2$)$. The $\mathrm{Cd}-\mathrm{Cl}$ distances varied between 2.5226 (12) and 2.7465 (12) $\AA$ with an average of $2.6465 \AA$. However, the organic part of the $\left(\mathrm{C}_{6} \mathrm{H}_{10} \mathrm{~N}_{2}\right)_{2} \mathrm{Cd}_{3} \mathrm{Cl}_{10}$ compound was formed by one type of cation, i.e. $\left(\mathrm{C}_{6} \mathrm{H}_{10} \mathrm{~N}_{2}\right)^{2+}$. The selected measured bond lengths and bond angles are grouped in Table 2. The organic molecule exhibited a regular spatial configuration with normal C-C and 
C-N distances in the range between $1.368(6)$ and $1.482(5) \AA$ respectively and C-C-C and CC-N angles which were in the range between $118.2(3)^{\circ}$ and $121.6(3)^{\circ}$, respectively. These values are in good agreement with those observed in similar compounds [28] and [29].

The structural analysis reveals that the stabilization of the whole supra-molecular assembly has been built up by the hydrogen bonds interaction. All hydrogen bondings are summarized in Table 3. A packing diagram (Fig. 4) of $\left(\mathrm{C}_{6} \mathrm{H}_{10} \mathrm{~N}_{2}\right)_{2} \mathrm{Cd}_{3} \mathrm{Cl}_{10}$ structure shows the presence of various hydrogen bonds between the organic cation and the chlorine atoms of the inorganic part which are linked by classic bonds $(\mathrm{N}-\mathrm{H} . . . \mathrm{Cl})$ involving the hydrogen atoms of the $\mathrm{NH} 3+$. The $\mathrm{N} \cdots \mathrm{Cl}$ distances varied between $3.121 \AA$ and $3.260 \AA$ and the $\mathrm{N}-\mathrm{H}-\mathrm{Cl}$ angle values varied from $151.68^{\circ}$ to $165.36^{\circ}$.

\subsection{Hirshfild surface analysis}

In the present research, we invested Hirshfeld surfaces and 2D fingerprint plots; we make use of Crystal Explorer, in order to identify intermolecular interactions and the environments of the components in the unit cell.

The dnorm, di, de, curvedness and shape index curves mapped on Hirshfeld surface for visualizing the intermolecular interactions are shown in the Figure. 5.

The 2D fingerprint plots of $\left(\mathrm{C}_{6} \mathrm{H}_{10} \mathrm{~N}_{2}\right)_{2} \mathrm{Cd}_{3} \mathrm{Cl}_{10}$ (Fig. S1), which analyses the strong indication for all intermolecular contacts, revealed that the main intermolecular interactions were contacts.

The fingerprint plots for different atom-atom contacts and the percentage contribution of each contacts to the Hirshfeld surfaces in the title compound showed that the contribution to the Hirshfeld surfaces from different contact id different (Fig. S2). Globally, $\mathrm{H} \cdots \mathrm{Cl}$ and $\mathrm{H} \cdots \mathrm{H}$ intermolecular interactions were the most abundant in the crystal packing $(55.7 \%$ and $11.6 \%$, respectively). This is evidence that van der Waals forces exert an important influence on the stabilization of the packing in the crystal structure, other intercontacts, such as $\mathrm{Cd} \cdots \mathrm{Cl}$ 
(11.4\%), $\mathrm{Cl} \cdots \mathrm{Cl}(5.3 \%), \mathrm{C} \cdots \mathrm{C}(4.4 \%)$ and $\mathrm{C} \cdots \mathrm{H}(0.7 \%)$, contribute less to the Hirshfeld surfaces.

\subsection{Molecular electrostatic potential}

The molecular electrostatic potential (MEP) is an important property that can be derived from electron density distribution. MEP is generated using the Avogadro software [29], on an asymmetric unit. The MEP is used as reactivity map displaying most probable regions for the electrophilic Attack of charged point-like reagents on hybrid molecules $[30,31]$. The blue and red colors indicate the positive and negative potentials, respectively. Fig. 6 shows that a positive electrostatic potential is localized over the organic cation while the $\mathrm{Cd}_{3} \mathrm{Cl}_{10}$ part is more electronegative.

Based on this result we can say that there is a global electrostatic attraction between the $\mathrm{Cd}_{3} \mathrm{Cl}_{10}$ anion and the organic cation which adds up to the favorable $\mathrm{H} \cdots \mathrm{Cl}$ hydrogen bonding.

\subsection{X-Ray Powder Diffraction Patterns}

The XRPD pattern of the $\left(\mathrm{C}_{6} \mathrm{H}_{10} \mathrm{~N}_{2}\right)_{2} \mathrm{Cd}_{3} \mathrm{Cl}_{10}$ compound is shown in Fig 7 . The sample is of single phase without any detectable impurity and narrow peaks indicate the good crystallinity of the material. The overlayed simulated XRD pattern using single crystal XRD data closely resembles the experimental pattern. Most of the peak positions in powder XRD and simulated pattern from single crystal XRD coincide.

\subsection{Scanning Electron Microscopic study of the sample}

Surface morphology of the grown crystal of $\left(\mathrm{C}_{6} \mathrm{H}_{10} \mathrm{~N}_{2}\right)_{2} \mathrm{Cd}_{3} \mathrm{Cl}_{10}$ was investigated by means of scanning electron microscope (SEM). The surface morphology and particle size of the title compound 'bis Orthophenylene diammonium dichloro tricadmate' are given in Fig. 8(a,b). 
From the SEM micrographs, we can see an assembly of crystal fragments which have a uniform distribution and have a flat surface which indicates good crystal quality. SEM images were taken at $80 \mathrm{x}$ and 350x magnifications with an acceleration voltage of $3-4 \mathrm{kV}$.

The EDX spectrum of the title compound revealed the presence of all non-hydrogen atoms: Cadmium, Chloride, Carbon, Nitrogen and Oxygen. Element analysis for the observed atoms was $\mathrm{C}: 15.2 \%, \mathrm{~N}: 7.1 \%, \mathrm{Cd}: 37.2 \%$ and $\mathrm{Cl}: 38.27 \%$, while the calculated values were $\mathrm{C}$ : $15.8 \%, \mathrm{~N}: 6.14 \%, \mathrm{Cd}: 36.97 \%$ and $\mathrm{Cl}: 38.86 \%$ (Fig. 8(c)).

\subsection{Infrared Spectroscopy}

In order to give information about the crystal structure, its vibrational properties were studied using infrared (IR) spectroscopy performed at room temperature. The analysis of the internal modes of the organic cations and the assignment were evaluated by comparing them with the spectra of homologous organic-inorganic compounds [32-35].

The IR spectrum reported in Fig. 9, shows at higher wave number absorption peaks at 3372 and $3049 \mathrm{~cm}^{-1}$ which are assigned to the symmetric and asymmetric stretching vibrations of the amine groups $\left(\mathrm{NH}_{3}\right)$. The bands between 2922 and $2803 \mathrm{~cm}^{-1}$ are assigned to $(\mathrm{C}-\mathrm{H})$ stretching modes. The strong bands observed between $2608 \mathrm{~cm}^{-1}$ and $2345 \mathrm{~cm}^{-1}$ in the experimental IR spectrum can be assigned to $v_{\mathrm{s}}\left(\mathrm{NH}^{+}\right)$. The band in the 1492, 1309 and 1243 $\mathrm{cm}^{-1}$ range are caused by the stretching vibration $v(\mathrm{C}=\mathrm{C})$ of the aromatic ring. Furthermore, the bands at 1148,1104 and $781 \mathrm{~cm}^{-1}$ were associated with $v(\mathrm{C}-\mathrm{N}), v(\mathrm{C}-\mathrm{C})$ and $\delta(\mathrm{C}-\mathrm{H})$, respectively. The low intensity band that appears at $752 \mathrm{~cm}^{-1}$ corresponds to the out of plane twist $\tau(\mathrm{C}-\mathrm{H})$.While the band observed at $583 \mathrm{Cm}^{-1}$ is attributed to $\mathrm{C}-\mathrm{C}$ scissoring. The band observed at $524 \mathrm{~cm}^{-1}$ corresponds of the out of plan twist $\tau(N H 3)$. Finally the band that appears at $444 \mathrm{~cm}^{-1}$ is due to the $\beta$ band $(\mathrm{C}-\mathrm{N})$ in the bending plane (Table 4). 


\subsection{CP/MAS-NMR Spectroscopy}

Nuclear magnetic resonance (NMR) is a very versatile technique used for the identification of organic compound. The ${ }^{13} \mathrm{C}$ CP-MAS NMR spectrum of bis Orthophenylediamonuim recorded between 0 and 200 ppm, reported in Fig 10, is in good agreement with the X-ray structure. Referring to studies in the literature $[36,37]$, it exhibited three signals for three different carbon environments. This shows the existence of only one organic cation in the asymmetric unit of the compound. The signal at about 120.99 ppm corresponds to the carbon atoms $C(4)$ and $C(5)$, the next signal is assigned to the $C(3)$ and $C(6)$ carbons approximately at $123.64 \mathrm{ppm}$ and the higher chemical shift value, $129.50 \mathrm{ppm}$, can be explained by the fact that the two carbon atoms $\mathrm{C}(1)$ and $\mathrm{C}(2)$ of the cyclohexane ring, are linked to the electronegative nitrogen atoms (Table 5), while the peaks at $40 \mathrm{ppm}$ correspond to the presence of dimethyl sulfoxide (DMSO).

\subsection{Optical properties}

The absorption spectra of the studied compound measured at room temperature are given in Fig. 11, which show two absorption bands centered at $497 \mathrm{~nm}(3.35 \mathrm{ev})$ and $252 \mathrm{~nm}(4.92$ $\mathrm{eV})$. The first peak is assigned to the exciton emission from the inorganic layers of $\mathrm{Cd}_{3} \mathrm{Cl}_{10}$ which is very similar to those found in other organic-inorganic hybrid compounds [38, 39]. Under excitation, an electron is excited from the valence band (VB) to the conduction band (CB), leaving a hole in the VB. The electron's transition back to the ground, which is the recombination of the electron and hole, yields an absorption bands centered at $497 \mathrm{~nm}$, while an emission of the peak at $252 \mathrm{~nm}$ is due to band gap absorption. Detailed optical properties of the structure of $\left(\mathrm{C}_{6} \mathrm{H}_{10} \mathrm{~N}_{2}\right)_{2} \quad \mathrm{Cd}_{3} \mathrm{Cl}_{10}$ including the diffuse reflectance and the photoluminescence are needed in order to check these assumptions. 


\subsection{Photoluminescence}

Hybrid organic-inorganic compound are promising photoluminescent materials due to the structural diversity and dimensional variability in the anion structures. The combination of metal and organic centers in inorganic-organic compounds provides an excellent route to a new type of photoluminescent materials. In this case, it is well known that coordination complexes with $\mathrm{d}^{10}$ metal configuration may be regarded as good candidates for potential photoactive materials [40]. The photoluminescence spectrum (Fig. 12) shows one band of luminescence located at $601 \mathrm{~nm}(2.06 \mathrm{eV})$ when excited at $341 \mathrm{~nm}$. This band can be even observed with naked eye at room temperature and is due to exciton emission $[41,42]$. The luminescence originates from electronic transition within the chlorocadmate inorganic $\mathrm{Cd}_{3} \mathrm{Cl}_{10}$ part. In the cadmium chloride based hybrid, the lowest exciton state arises from excitation between the VB, which consists of a mixture of $\mathrm{Cd}(5 \mathrm{~s})$ and $\mathrm{Cl}(3 \mathrm{p})$ states, and the conduction band $(\mathrm{CB})$, which derives primarily from $\mathrm{Cd}(5 \mathrm{p})$ states. Under excitation of $491 \mathrm{~nm}$ irradiation, an electron (-) is excited from the VB to the $\mathrm{CB}$, leaving a hole (+) in the VB. The exciton (-) and the hole (+) move freely in the CB and VB, forming an exciton. The recombination of the electron and hole in the exciton yielded a red emission at $601 \mathrm{~nm}$ (Fig. S3) with a life time $\tau=3 \mathrm{~ns}(+-0.08 \mathrm{~ns})$ that is estimated by fitting the decay curve with a mathematical model, according to the general formula $\mathrm{I}=\mathrm{I} 0 \mathrm{e}^{(-\mathrm{t} / \tau) \text { where }} \tau$ is the lifetime (Fig. S4).

\section{Conclusion}

We successfully fabricated a special inorganic-organic hybrid, bis (ortho phenylendiamonuim) dodecachlorotricadmate $\left(\mathrm{C}_{6} \mathrm{H}_{10} \mathrm{~N}_{2}\right)_{2} \mathrm{Cd}_{3} \mathrm{Cl}_{10}$. This new organicinorganic compound crystallized in the triclinic system with $P-1$ space group at room temperature, whose structural arrangement can be described as an alternation of organic- 
inorganic layers that is performed via $\mathrm{N}-\mathrm{H} \cdots \mathrm{Cl}$ hydrogen bonding. Hirshfeld surface analysis and fingerprint plots indicate that the structure is stabilized by intermolecular interactions. The powder XRD is homogeneous with single-crystal. Moreover, the infrared spectra confirm the presence of both cationic $\left(\mathrm{C}_{6} \mathrm{H}_{10} \mathrm{~N}_{2}\right)$ and the NMR spectroscopy proved to give a rather

good insight of the chemical shift relative to ${ }^{13} \mathrm{C}$. The studies of optical and luminescence activities reveal that this compound exhibits high stability and has potential applications. Further experimental research will be conducted to synthesize other hybrid materials with interesting properties for as a potential for various applications in different domains.

\section{Supporting information available}

Crystallographic data for the structural analysis have been deposited with the Cambridge Crystallographic data Center, CCDC 1451708 for the complex. Copies of the data can be obtained free of charge at www.ccdc.cam.ac.uk/conts/retrieving.html.

\section{Acknowledgments}

Financial support from Faculty of Science in University of Gabes, Tunisia, Spanish Ministerio de Economía y Competitividad (MINECO-13-MAT2013-40950-R, and FPI grant BES-2011046948 to MSM.A.) and Gobierno del Principado de Asturias (GRUPIN14-060), are acknowledged. 


\section{References}

[1] L. M. Wu, X. T. Wu, \& Chen, Coord. Chem. Rev. 253 (2009) 2787-2804.

[2] D.B. Mitzi, P. Brock, Inorg. Chem. 40 (2001) 2096-2104.

[3] N. Louvain, N. Mercier, F. Boucher, Inorg. Chem. 48 (2009) 879-888.

[4] B. Kulicka, R. Jakubas, A. Pietraszko, W. Medycki, J. Swiergiel, J Mol Struct. 783 (2006) 88-95.

[5] R.D. Willet, E.F. Riedel, Chem. Phys. 8 (1975) 112-122.

[6] A. Jarboui, B. Louati, F. Hlel, K. Guidara, J. Alloys Compd. 503(2010) 340-344.

[7] N. Hannachi, K. Guidara, A. Bulou, F. Hlel, Materials Research Bulletin. 45 (2010) 17541761.

[8] V. de Zea Bermudez, L.D. Carlos, M.C. Duarte, M.M. Silva, C.J. Silva, M.J. Smith, M. Assuncao, L. Alcacer, J. Alloys Compd. 21 (1998) 275-277.

[9] L.D. Carlos, R.A. Sa Ferreira, V. de Zea Bermudez, S.J.L. Ribeiro, Adv. Funct. Mater. 2 (2001) 111-115.

[10] Y. Kato, D. Ichii, K. Ohashi, H. Kunugita, K. Ema, K. Tanaka, T. Takahashi, T. Kondo, Solid State Commun. 128(2003) 15-18.

[11] A. El-Korashy, M.G. BriK, Solid State Commun. 135 (2005) 298-303.

[12] A. Ben Rhaiem, F. Hlel, K. Guidara, M. Gargouri, J. Alloys Compd. 463 (2008) 440445.

[13] A.B. Corradi, A.M. Ferrari, G.C. Pellacani, Inorg. Chim. Acta. 272 (1998) 252.

[14] F. Neve, O. Francescangeli, A. Crispini, Inorg. Chim. Acta. 338 (2002) 51-58.

[15] S. Kuriyama, Y. Inomata, Y. Arai, F.S. Howell, J. Inorg. Biochem. 100 (2006) 1299-1307.

[16] A. Lamhamdi, E. Mejdoubi, K. Fejfarova, M. Dus_ek, B. El Bali, Acta Cryst. E65 (2009) m215-m216. 
[17] C. J. Adams, M. A. Kurawa, A. G. Orpen, Inorg. Chem. 49 (2010) 10475-10485.

[18] A. G-Raso, J. J. Fiol, A. Tasada, F. M. Albertí, F. Bádenas, X. Solans, M. F-Bardia, Polyhedron . 26 (2007) 949-957.

[19] L.J. Farrugia, J. Appl. Cystallogr. 32 (1999) 837-838.

[20]G.M. Sheldrick, SHELXS-86, Program for Crystal Structure Solution, University of Göttingen, Germany (1986).

[21] G.M. Sheldrick, SHELXL-97, Program for Crystal Structure Refinement, University of Göttingen, Germany (1997).

[22] K. Brandenburg, Diamond Version 4.0.2 Impact Gbr, Bonn, Germany, 2015.

[23] J. Louis. Farrugia, J. Appl. Cryst. 45 (2012) 849-854.

[24] O.S. Urgut, I.I. Ozturk, C.N. Banti, N. Kourkoumelis, M. Manoli, A.J.Tasiopoulos, S.K. Hadjikakou, Mater. Sci. Eng. C Mater. Biol. Appl. 58 (2015) 396-408.

[25] O.S. Urgut, I.I. Ozturk, C.N. Banti , N. Kourkoumelis , M. Manoli , A.J. Tasiopoulos, S.K. Hadjikakou; InorganicaChimicaActa. 443 (2016) 141-150.

[26] S. K. Wolff, D. J. Grimwood, J. J. McKinnon, M. J. Turner, D. Jayatilaka and M. A. Spackman; Crystal Explorer (2012) The University of Western Australia, Australia.

[27] M. S. Lassoued, W. Ben Soltan, Mohammed S. M. Abdelbaky, S. Ammar, A. Gadri, A. Ben Salah, S. Garcia Granda. J. Matter. Sci 1120 (2017) 12896-12710.

[28] M. S. Lassoued, Mohammed S. M Abdelbaky, A. Lassoued, A. Gadri, S. Ammar, A. Ben Salah, S. Garcia Granda. J. Mol. Struct.1141 (2017) 390-399.

[29] M. D. Hanwell, D. E. Curtis, D. C. Lonie, T. Vandermeersch, E. Zurek, G. R, Hutchison, J. Cheminform. 4 (2012) 1-17.

[30] M . S. Lassoued, Mohammed S. M Abdelbaky, A. Lassoued, R. Mendoza merona, A. Gadri, S. Ammar, A. Ben Salah, S. Garcia Granda. J. Mol. Struct. 1141(2017) 660-667. 
[31] M. S. Lassoued, Mohammed S. M Abdelbaky, R. Mendoza merona, A. Gadri, S. Ammar, A. Ben Salah, S. Garcia Granda. J. Mol. Struct, 1142(2017) 73-79.

[32] A. Kessentini, M. Belhouchet, J.J. Suñol, Y. Abid, T. Mhiri, Luminescence. 149 (2014) 341-347.

[33] R. Elwej, N. Hannachi, I. Chaabane, A. Oueslati, F. Hlel, J. Inorg. Chim. Acta. 406 (2013) 10-19.

[34] R.Hajji, A. Oueslati, N.Errien, F.Hlel, Polyhedron. 79 (2014) 97-103.

[35] R. Elwej, N. Hannachi, I. Chaabane, A. Oueslati, F. Hlel , J. Inorg. Chim. Acta. 406 (2013) 10-19.

[36] A. Tounsi, B. Hamdi, R. Zouari, A. Ben Salah, Physica E 84 (2016) 384-394.

[37] N. Karaa, B. Hamdi, A. Ben Salah, R. Zouari, J. Mol. Struct. 1049 (2013) 48-58.

[38] C. Hrizi, N. Chaari, Y.Abid, N. Chniba-Boudjada, S. Chaabouni, Polyhedron. 46 (2012) $41-46$.

[39] A.C. Dhieb, A. Valkonen, M. Rzaigui, W. Smirani, J. of Mol. Struct.1102 (2015) 50-56.

[40] J. Chen, M-Ze Li, N. Sun, J-Hua Guo, J. of Mol. Struct. 1105 (2016) 273-278.

[41] H-F. Chen, M-J. Zhang, M-S. Wang, W-B. Yang, X-G. Guo, C-Z. Lu, Inorganic Chemistry Communications. 23 (2012) 123.

[42] S. V. Larionov, T. E. Kokina, V. F. Plyusnin, L. A. Glinskaya, A. V. Tkachev, Y. A. Bryleva, N. V. Kuratieva, M. I. Rakhmanova, E. S. Vasilyev, Polyhedron. 77 (2014) 75-80. 


\section{Table Captions}

Table 1 Crystal data and structure refinement for $\left(\mathrm{C}_{6} \mathrm{H}_{10} \mathrm{~N}_{2}\right)_{2} \mathrm{Cd}_{3} \mathrm{Cl}_{10}$ crystal

Table 2 Selected bond distances $[\AA]$ and angles $\left[{ }^{\circ}\right]$ in $\left(\mathrm{C}_{6} \mathrm{H}_{10} \mathrm{~N}_{2}\right)_{2} \mathrm{Cd}_{3} \mathrm{Cl}_{10}$

Table 3 Main interatomic distances $(\AA)$ and bond angles $\left(^{\circ}\right)$ involved in hydrogen bonds (e.s.d. are given in parentheses)

Table 4 Observed vibration frequencies $\left(\mathrm{cm}^{-1}\right)$ and band assignments for $\left(\mathrm{C}_{6} \mathrm{H}_{10} \mathrm{~N}_{2}\right)_{2} \mathrm{Cd}_{3} \mathrm{Cl}_{10}$

Table 5 The chemical shifts of the carbons atoms in the ${ }^{13} \mathrm{C}$ NMR spectrum of $\left(\mathrm{C}_{6} \mathrm{H}_{10} \mathrm{~N}_{2}\right)_{2} \mathrm{Cd}_{3} \mathrm{Cl}_{10}$

\section{Figure Captions}

Fig. 1 The asymmetric unit of $\left(\mathrm{C}_{6} \mathrm{H}_{10} \mathrm{~N}_{2}\right)_{2} \mathrm{Cd}_{3} \mathrm{Cl}_{10}$ showing the atom-labeling scheme

Fig. 2 The atom-labeling of the $\left[\mathrm{Cd}_{3} \mathrm{Cl}_{10}\right]$ chain structure for $\left(\mathrm{C}_{6} \mathrm{H}_{10} \mathrm{~N}_{2}\right)_{2} \mathrm{Cd}_{3} \mathrm{Cl}_{10}$ crystals

Fig. 3 Crystal packing of $\left(\mathrm{C}_{6} \mathrm{H}_{10} \mathrm{~N}_{2}\right)_{2} \mathrm{Cd}_{3} \mathrm{Cl}_{10}$ compound in 'ab' plane

Fig. 4 Perspective view of the $\left(\mathrm{C}_{6} \mathrm{H}_{10} \mathrm{~N}_{2}\right)_{2} \mathrm{Cd}_{3} \mathrm{Cl}_{10}$ compound according to (b, c) plane (the red lines represent hydrogen bonds)

Fig. 5 The Hirshfeld surfaces mapped with d norm, di, de, Shape index and Curvedness for the title compound

Fig. 6 Electrostatic potential (red: negative potential, blue: positive potential)

Fig. 7 Simulated and experimental XRD patterns of $\left(\mathrm{C}_{6} \mathrm{H}_{10} \mathrm{~N}_{2}\right)_{2} \mathrm{Cd}_{3} \mathrm{Cl}_{10}$

Fig. $8 \mathrm{MEB}$ (a and b) and EDXS (c) images of $\left(\mathrm{C}_{6} \mathrm{H}_{10} \mathrm{~N}_{2}\right)_{2} \mathrm{Cd}_{3} \mathrm{Cl}_{10}$

Fig. 9 FT-IR spectra of $\left(\mathrm{C}_{6} \mathrm{H}_{10} \mathrm{~N}_{2}\right)_{2} \mathrm{Cd}_{3} \mathrm{Cl}_{10}$

Fig. $10{ }^{13} \mathrm{C}$ CP-MAS NMR spectrum of $\left(\mathrm{C}_{6} \mathrm{H}_{10} \mathrm{~N}_{2}\right)_{2} \mathrm{Cd}_{3} \mathrm{Cl}_{10}$ in DMSO

Fig. 11 Absorption of $\left(\mathrm{C}_{6} \mathrm{H}_{10} \mathrm{~N}_{2}\right)_{2} \mathrm{Cd}_{3} \mathrm{Cl}_{10}$ at room temperature

Fig. 12 Excitation and emission fluorescence profile (Excitation black and emission red) 